Proceedings of ASME Turbo Expo 2016: Turbomachinery Technical Conference and
Exposition
GT2016
June 13-17, 2016, Seoul, South Korea

GT2016-56100

\title{
AN OVERVIEW OF LOW-EMISSION COMBUSTION RESEARCH AT NASA GLENN
}

\author{
Dhanireddy R. Reddy and Chi-Ming Lee* \\ NASA Glenn Research Center \\ Cleveland, $\mathrm{OH}$ \\ U.S.
}

\begin{abstract}
$\underline{\text { Abstract }}$
An overview of research efforts at NASA Glenn Research Center (GRC) in low-emission combustion technology that have made a significant impact on the nitrogen oxides (NOx) emission reduction in aircraft propulsion is presented. The technology advancements and their impact on aircraft emissions are discussed in the context of NASA's Aeronautics Research Mission Directorate (ARMD) high-level goals in fuel burn, noise and emission reductions. The highlights of the research presented here show how the past and current efforts laid the foundation for the engines that are flying today as well as how the continued technology advancements will significantly influence the next generation of aviation propulsion system designs.
\end{abstract}

\section{$\underline{\text { Introduction }}$}

NASA has been at the forefront of the nitrogen oxide (NOx) reduction effort in the aviation industry over the last 4 decades, resulting in approximately $50 \%$ reduction about every 15 years (Lee et al. 2013). The initial concern was the local air standard leading to health issues such as ground-level NOx and its contribution to photochemical smog (Fig. 1). As a result, a series of increasingly stringent NOx emission standards by the International Civil Aviation Organization's (ICAO) Committee on Aviation Environmental Protection (CAEP) has, over the years, served as the basis for regulation of aviation emissions below 3,000-foot altitude. These standards cover the take-off, climb, descent, and taxiing/ground idle phases of the engine operation, the so- called landing and take-off (LTO) cycle, in a prorated fashion. The aviation propulsion

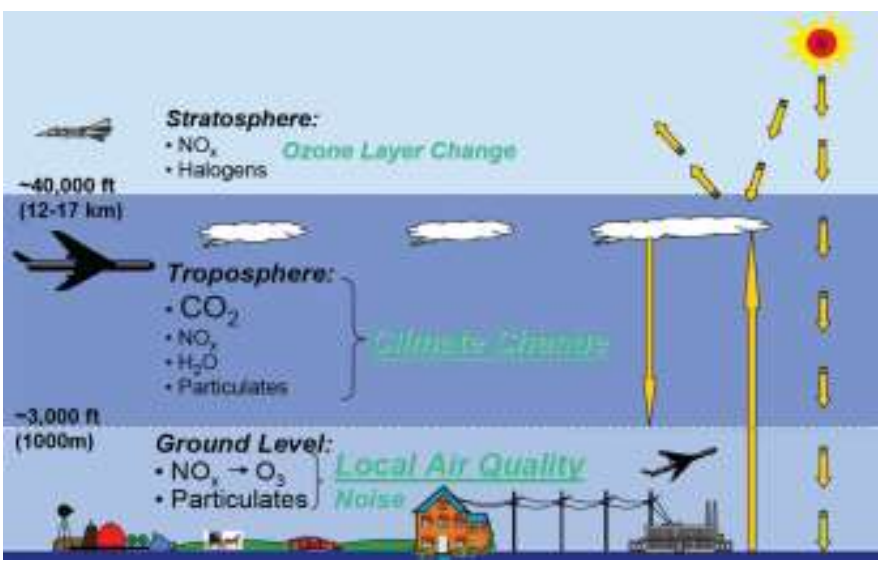

Fig. 1 Impact of Aviation on the Environment

industry has taken advantage of the NASA-sponsored technology and the resulting combustor concepts by turning these concepts into flight hardware through collaboration with NASA wherever possible (Fig. 2).

The continuing NOx reduction effort is part of NASA's Aeronautics Research Mission Directorate's (ARMD) plan that sets the direction for the nation's research priorities and long-term objectives for the benefit of the public in the area of civil aviation (NASA's New Aeronautics Research Program Overview (2007) and Program Highlights Fundamental

\section{* Retired from NASA Glenn Research Center}

This material is declared a work of the U.S. Government and is not subject to copyright protection in the United States. Approved for public release; distribution is unlimited. 
Aeronautics Program (Alonso 2008)). The detailed technology

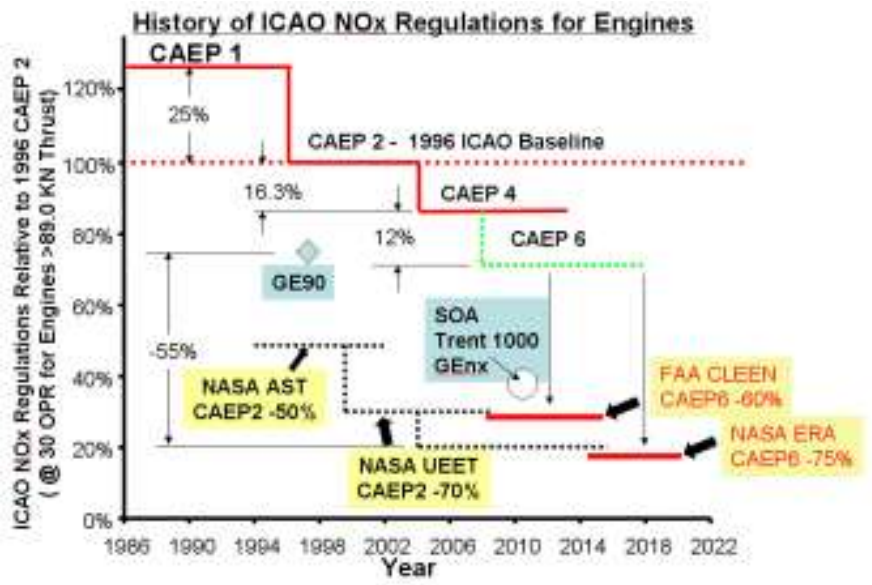

Fig. 2 History of NOx Regulations

development plans call for significant gain in fuel efficiency with minimal impact on the environment in the near-term to long-term time scale extending to 2035. These plans specify quantitative goals for fuel burn, emissions (NOx, particulate, and green-house gases), and noise reduction targeted to be achieved through technology advancement in the time-frames identified for near-, mid-, and long-terms (Alonso 2008).

Although fuel efficiency and noise reduction contributions can come from both air frame and propulsion systems

technologies, emission reduction can only be achieved through propulsion technology advancement. NASA Glenn Research Center, with air-breathing propulsion as one of its core competencies, has played a key role in advancing the lowemission combustion technology. The objective of this paper is to present an overview of the low-emission combustion research that has made a significant impact on the NOx reduction as well as current efforts underway at NASA Glenn Research Center. It is worth noting that similar technology development plans for fuel efficiency improvement as well as emission and noise reduction with quantitative goals have been adapted by European Union. The European Union Advisory Council for Aviation Research in Europe (ACARE) also has numerical targets for reductions in $\mathrm{CO}_{2}$ and $\mathrm{NOx}$ emissions and also noise for 2050 compared to the datum of 2000 as part of their Flight Path 2050 initiative (Parker 2015). A number of collaborative efforts involving the European industry and government agencies have been underway to meet these goals (Parker 2015; Runnemalm 2015; Remy 2015; Singh 2015)

\section{Key Factors in NOx Formation}

Mixing of fuel and air before burning starts has a strong influence on what a combustor emits. In aircraft engines, fuel from the fuel injectors is sprayed in as liquid, and it needs to vaporize and mix with the air before burning can occur. A very non-uniform mixture, with some pockets being too fuelrich and some too fuel-lean, can lead to unacceptable levels of carbon monoxide (CO), unburned hydrocarbons, and soot due to quenching or inadequate residence times to achieve complete burnout. In contrast, some near-stoichiometric pockets of fuel-air mixtures will burn very hot and produce NOx very quickly. Since NOx emission level is the time integral of the nitrogen-oxide's formation rate, the latter being an exponential function of the air temperature, NOx emission level correlates very well to the fuel injector's ability to prepare the fuel-air mixture. Mixing the fuel with air as quickly and uniformly as possible before burning starts is a key factor for clean burning. The technical challenge is to accomplish it during the available time, which must decrease with increasing temperature and pressure due to risk of autoignition.

The most common method of achieving faster fuel-air mixture is injection of fuel through smaller holes in fuel injectors to speed up breakup and vaporization. However, as fuel heats up going through the fuel passage, eventually some components in the fuel reacts with the dissolved oxygen and breakdown into a gummy substance, which in time turns into carbon buildup (coking) that blocks the fuel passage. Increasing the overall pressure ratio (OPR) of the engine cycle increases the air temperature and speeds up coking. The availability of alternative hydrocarbon fuels that don't coke easily enables the use of smaller injection passages to speed up fuel-air mixing process.

Every fuel injector also has its own combustion dynamics characteristics resulting from the interaction of fluid dynamics with the combustion process. When the time scale and phase match, they can interact with the combustor acoustics to set up instabilities or limit-cycle behavior that can result in severe pressure oscillations or disruption of the normal flame stabilization process. Thus, designing a fuel injector that mixes fuel with air quickly, resists coke formation, and burns stably over a wide range of power conditions is the key for the new generation of cleaner-burning combustors for future aircraft engines.

Higher OPR combustion will need combustor liners able to withstand higher temperatures. Ceramic matrix composite (CMC) liner materials and environmental barrier coatings (EBC) are complementary enabling technologies to the new injectors. A CMC liner can withstand higher temperatures than a traditional metal liner, while needing less cooling air. This capability allows the extra air to be used in the fuel injector to increase fuel-air mixing, which in turn provides a more uniform mixture with fewer hot spots such that the liner needs less air for cooling. EBCs protect the CMC surfaces from oxidation as well as allow the CMC liner to operate cooler, thus extendig the liner life.

\section{Glenn Experimental and Computational Tools}

NASA GRC operates several high-pressure test facilities (Bianco 1995) to investigate combusting flows under realistic overall pressure ratio (OPR) conditions, evaluate contractordelivered hardware, and from time to time help industry debug problems. The Advanced Subsonic Combustion Rig (ASCR), developed in the late 1990s, enables high pressure testing of sector-type combustors up to 60 atm and $1300^{\circ} \mathrm{F}$ inlet conditions. Recently, two combustor sectors from General Electric and Pratt \& Whitney have been tested in the ASCR under the current NASA Environmentally Responsible 
Aviation (ERA) project phase I, which will be discussed in the later part of the paper. The flame tube test facility, CE-5, allows investigation of new combustor concepts in a moderate high-pressure environment of up to $30 \mathrm{~atm}$. Multi-injector combustor sectors can also be tested in CE-5 with access for a variety of optical and instrumented diagnostic tools. Optical access allows laser-based diagnostics to be used to investigate flow field and species distributions. Both CE-5 and ASCR can accommodate hardware testing with alternative fuel blends on the fly. Additional test facilities exist to perform fundamental and applied research aimed at advancing combustion process understandings. More recently, the advent of high-power lasers has enabled even more spectroscopic measurements in hydrocarbon-air flames for aircraft propulsion, providing greater spatial resolution and the ability to measure more species. These new capabilities allow us to carry out measurements to aid in combustion code validation. Fig. 3 shows some results from testing of one of the advanced injector concepts, lean direct injection (LDI) design, with different types of fuel in the CE-5 facility. NOx, CO, and combustion efficiency are shown in the plots in Fig. 3 for three different fuels and two different inlet temperatures. Open symbols represent the inlet temperature of $850^{\circ} \mathrm{F}$, and the solid symbols represent the inlet temperature of $1030^{\circ} \mathrm{F}$. The red, blue, and green colors represent $100 \%$ JP-8, 50/50 blend of JP-8 and Fischer-Tropsch (F-T), and 100\% F-T fuels, respectively. The NOx emission index, EINOx, is defined as grams of NOx emitted per kilogram of burnt fuel, and the $\mathrm{CO}$ emission index, EICO, is similarly defined as grams of $\mathrm{CO}$ per kilogram of burnt fuel. FAR in the x-axes of these plots refers to fuel-air ratio.

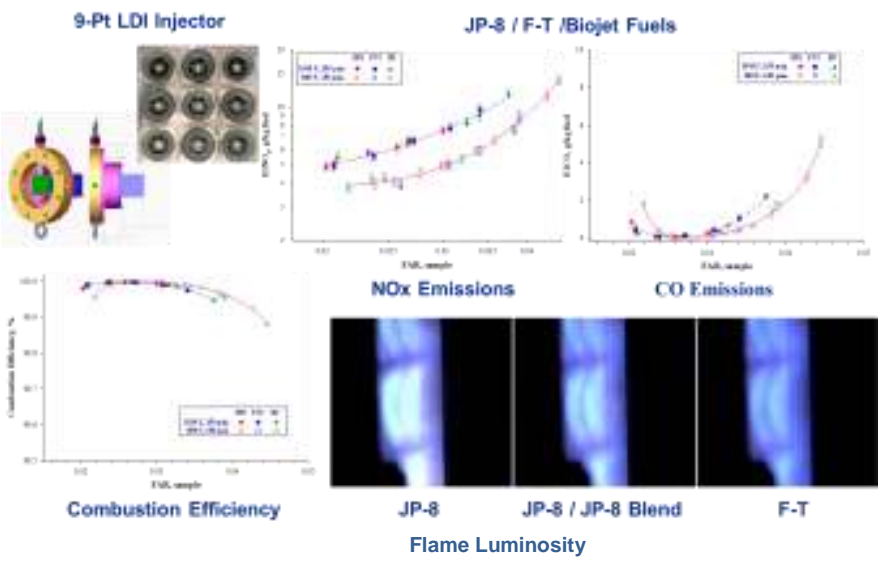

Fig. 3 CE-5B Medium-Pressure Flametube Testing

Luminosity in Fig. 3 was obtained using a color video to get a sense of which major constituents were emitting. In the visible region, emissions in the violet near $432 \mathrm{~nm}$ come mainly from $\mathrm{CH}$. The other primary chemical species that emits is $\mathrm{C} 2$, with Swan bands in the blue $(473 \mathrm{~nm})$, green $(516 \mathrm{~nm})$ and yellow (573-nm). The $\mathrm{CH}$ and $\mathrm{C} 2$ emissions are what we typically consider as the "clean" hydrocarbon flame colors, whereas orange generally indicates a sooty flame. Soot can be a problem because it detrimentally affects heat transfer to engine subcomponents. Also, particles that are not burnt off before leaving the combustor will carry on through the engine and be exhausted into the atmosphere. Whether or not soot is the predominant visible light emitter can be discerned qualitatively by observing the flame color via standard video. Video image results are displayed in Figure 3. The camera was angled so that parts of five LDI elements can be seen. Flow passes from left to right. The images from left to right are for $100 \%$ JP-8, a 50/50 blend of JP-8 and F-T, and 100\% F-T fuels. The yellowish color visible from soot can be seen in the $100 \%$ JP-8 image, but not so much in the $100 \%$ F-T image. The F-T flame is much bluer. These results are reasonable given that the F-T contains only $0.6 \%$ aromatics, and JP-8 contains up to $25 \%$ aromatics. The F-T fuel with $0.6 \%$ aromatics is a research fuel that is not certified and is used here to compare its luminosity with that of JP-8 (25\% aromatics).

Numerical simulation of reacting flows within an engine system where combustion takes place poses a difficult technical challenge because of the complex three-dimensional, highly turbulent, multi-phase, and chemically reacting environment. However, fully understanding this flow physics is critical to any effort in the aircraft engine combustor design and development process. Steady progress in computational fluid dynamics (CFD) technologies has enabled the modeling and simulation to become a complementary activity needed to support the insights obtained through testing. These insights are used to improve our understanding of key flow phenomena for any new combustor design efforts. The intent is to make smarter designs, to reduce the number of design iterations and testing time, and ultimately to speed up the combustion hardware development process. Starting in 1995, NASA Glenn has invested significant resources in the development of the National Combustion Code (NCC) to solve the complex combustion flow dynamics problems in gas turbine, rocket, and hypersonic engines. NCC capabilities include, among others, multi-component liquid sprays, primary fuel atomization models, secondary droplet breakup models, highpressure equations of state, superheated droplet vaporization, models for particulate emissions, integrated combustor-turbine simulation, and time-filtered Navier-Stokes simulations (TFNS). More detailed information can be found in the following references: Liu (2011), Wey and Liu (2011), Shih and Liu (2009), Raju and Bulzan (2011), and Liu et al. (2007).

The NCC code has been applied to compute the two-phase turbulent combustion occurring in a single-element LDI combustor mentioned above. Fig. 4 shows the illustration of this combustor along with the computational grid used for the computation. More

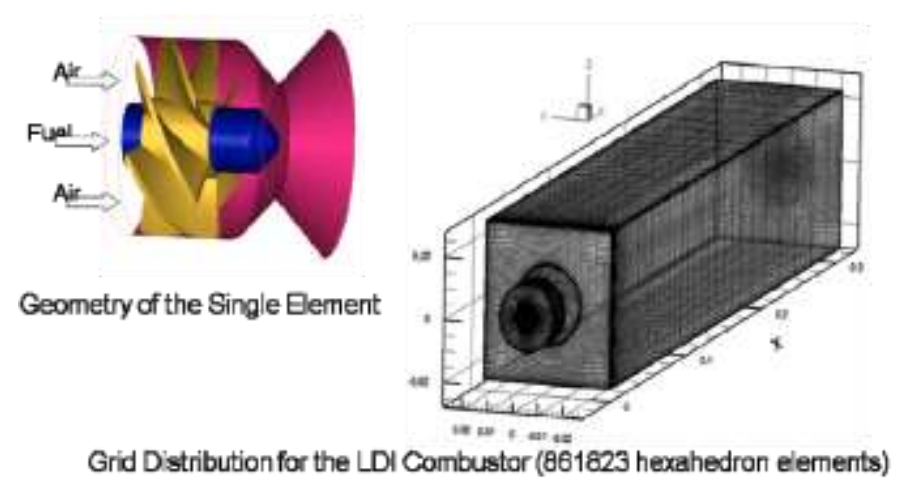




\section{Fig. 4 Geometry and Computational Domain of a Single-Element LDI Combustor}

detailed description of the combustor geometry and the test rig can be found in Cai, et al. (2005). Each element consists of an air passage with an upstream air swirler and a convergingdiverging venturi section. The fuel is injected through the center of the swirler and the fuel tip is at the throat of the venture. The air swirlers have six helical axial vanes with downstream vane angles of $60^{\circ}$. Fig. 5 shows the timeaveraged contour plots of the temperature field in the center plane $(\mathrm{z}=0)$ along with two snap-shot solutions of the instantaneous temperature.
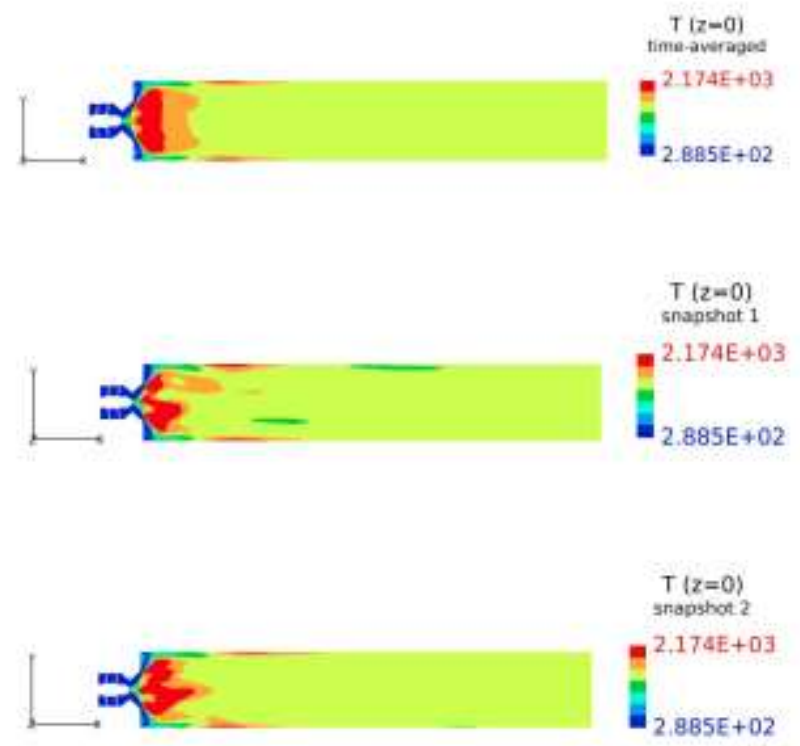

Fig. 5 Temperature Distribution in the Center Plane: Time-Averaged Field and Two Snapshots

Centerline-averaged temperature downstream of the dump plane (located at $\mathrm{x}=0.0072 \mathrm{~m}$ ) along the length of the combustor is shown in Fig. 6 in comparison with experimental data. The major cause of the discrepancy between computation and experiment, near the dump plane, is the spray injection and vaporization models, which are continually being enhanced to include more of the key flow physics in them.

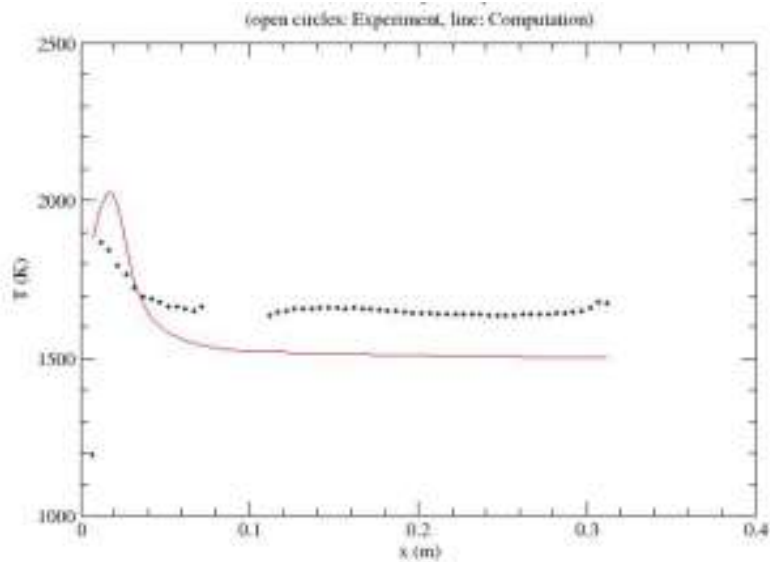

Fig. 6 Averaged Temperature Along the Center Line
The discrepancy at the exit is due to the old reduced chemistry model which was known to under-predict adiabatic flame temperature. The chemistry model has been revised in the current version of the code and is currently being validated. Radial profiles of time-averaged axial velocity, and averaged azimuthal velocity at further downstream locations are presented in Figs. 7 and 8 respectively. A comparison of computational results with the experimental data shows reasonably good agreement in general for the computational grid sizes used to simulate the complex injector design features, and it is believed that the discrepancies between the computed and experimental values could be reduced by better grid resolution in the cross section and in the near-wall region.

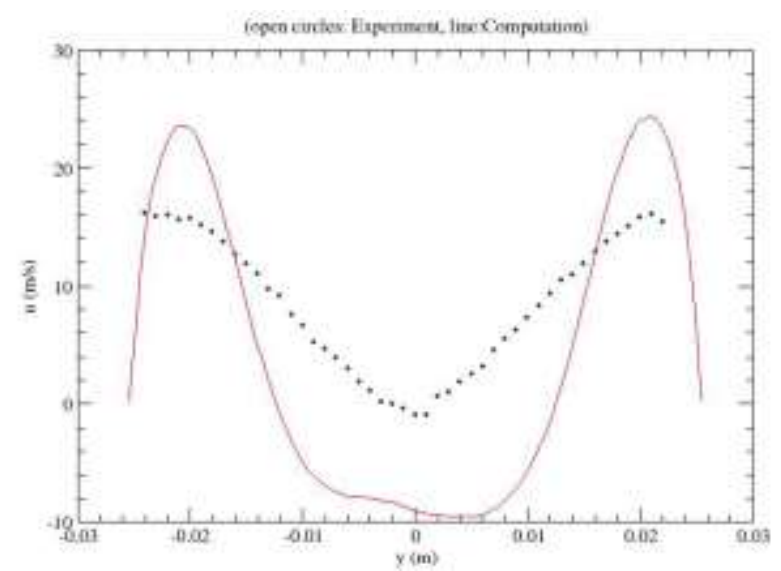

Fig. 7 Radial Profile of Averaged Axial Velocity (46 mm Downstream of the Dump Plane)

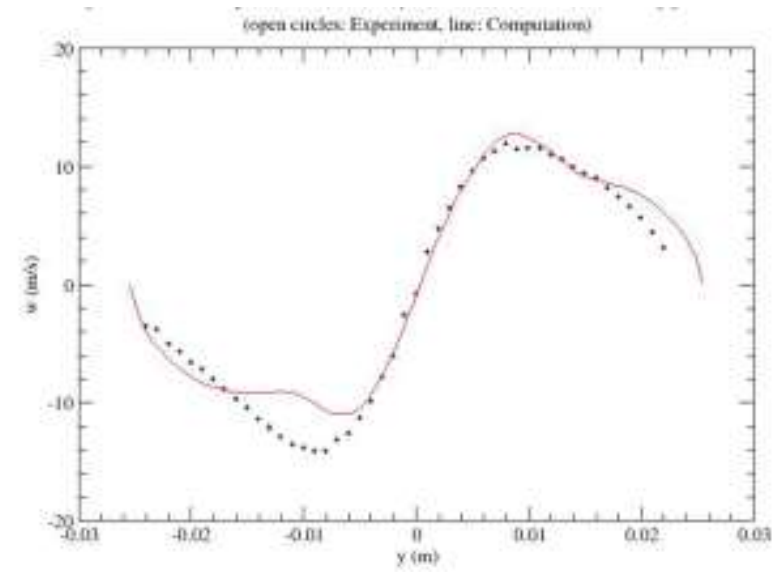

Fig. 8 Radial Profile of Averaged Azimuthal Velocity (46 mm Downstream of the Dump Plane)

\section{Early Research}

NASA Glenn Research Center, since its beginning as the NACA's Aircraft Engine Research Laboratory in 1941, has been involved in a wide range of combustor concept research, component technology development, and enabling technology development. The focus for the last 5 decades of NASA Glenn's combustion research has been in efforts to reduce and to better understand environment and health impact of aviation emissions. The in-house test facilities, combustor concept research, as well as collaborative focused programs with industry and academia provided the platforms for development 
of analytical tools, optical diagnostics, advanced fuels, and thermal management as enabling technologies. Some of these past and current efforts laid the foundation for the engines that we are flying today. Building better understanding and tools for combustion modeling as part of advanced propulsion systems to fly higher, faster, and farther will be the foundation of the next generation of propulsion systems.

Combustors of the jet engines in the 1960s were relics of the military engine technology. They smoked heavily because of the rich-burning combustor front ends designed for stable operation. NASA found that leaning out the primary reaction zone decreased the smoke number (Rudey and Kempke 1975). NASA's combustion research began to focus on reducing the emission of nitrogen oxides (NOx) at high power conditions as well as reduction of carbon monoxide (CO) and total unburned hydrocarbons (THC) at low-power conditions. NOx emissions have a significant impact on the local air quality around the airports (Fig. 1). Consequently, NOx emissions during landing and take-off (LTO) are regulated by the federal government. The limits on LTO NOx are set by the ICAO CAEP and are periodically revised as the technology to reduce emissions is continuously advanced (Fig. 2). To reduce high-power NOx emissions, NASA investigated (fuel) lean, premixed, prevaporized combustion (LPP), catalytic combustion (Szaniszlo 1979), and a partially premixed, distributed combustion concept called swirl can combustion (Jones and Grobman 1973, Rudey 1976). To reduce low-power CO and THC emissions, NASA investigated fuel scheduling, airblast and air assist fuel nozzles (Papathakos and Jones 1973), and catalytic combustion (Rudey 1976; Rudey and Kempke 1975; Mularz et al. 1978). While some of these technologies such as airblast and air assist fuel nozzles can be implemented nearterm, others such as LPP and catalytic combustion were the focus of longer term research programs (NASA CP-2108).

\section{Focused Research}

In addition to the in-house research, NASA collaborated with industry on several near-term emissions reduction combustor focused-programs starting in the mid-1970s to put some of the lessons learned earlier to use. Table 1 lists the major NASA combustor-focused programs chronologically, the technologies they researched, and their legacy products. The first two of these started within a year of the Environmental Protection Agency announcing standards for aircraft emissions to go into effect in 1979. The Experimental Clean Combustor (ECC) Program focused on large engines producing greater than $8,000 \mathrm{lb}$ of thrust.

Under the ECC program, industry partners General Electric (GE) and Pratt \& Whitney (P\&W) were contracted to study the feasibility of retrofitting their large engines with cleaner burning combustor concepts (Niedzwiecki and Jones 1974). GE and P\&W investigated low emissions combustor concepts and the "best" low-emissions combustor concepts to come out of that study were the dual-annular (DAC) concept, shown in Fig. 9(a) for GE and the Vorbix combustor, Fig. 9(b), for P\&W (Jones et al. 1978). Like NASA's LPP and catalytic combustion concepts, both the GE and P\&W concepts burned

\begin{tabular}{|c|c|c|c|c|}
\hline $\begin{array}{l}\text { Focused Program } \\
\text { Name }\end{array}$ & Year & $\begin{array}{l}\text { Targeted } \\
\text { Engine }\end{array}$ & $\begin{array}{l}\text { Combustor } \\
\text { Concepts }\end{array}$ & Legacy \\
\hline $\begin{array}{l}\text { Experimental } \\
\text { Clean Combustor } \\
\text { (ECC) }\end{array}$ & $\begin{array}{l}1973- \\
1978\end{array}$ & Large & $\begin{array}{l}\text { DAC, } \\
\text { Vorbix }\end{array}$ & \\
\hline $\begin{array}{l}\text { Pollution } \\
\text { Reduction } \\
\text { Technology } \\
\text { Program (PRT) }\end{array}$ & $\begin{array}{l}1974- \\
1979\end{array}$ & $\begin{array}{l}\text { Small to } \\
\text { Mid- } \\
\text { sized }\end{array}$ & Vorbix & \\
\hline $\begin{array}{l}\text { Quiet Clean } \\
\text { Short-Haul } \\
\text { Experimental } \\
\text { Engine Clean } \\
\text { Combustor } \\
\text { (QCSEE) }\end{array}$ & $\begin{array}{l}1974- \\
1975\end{array}$ & $\begin{array}{l}\text { Short- } \\
\text { haul }\end{array}$ & & \\
\hline $\begin{array}{l}\text { Stratospheric } \\
\text { Cruise Emission } \\
\text { Reduction } \\
\text { program } \\
\text { (SCERP) } \\
\end{array}$ & $\begin{array}{l}1977- \\
1983 \\
\end{array}$ & SST & LPP & \\
\hline $\begin{array}{l}\text { Energy Efficient } \\
\text { Engine (EEE, E3) }\end{array}$ & $\begin{array}{l}1980- \\
1984\end{array}$ & $\begin{array}{l}\text { High } \\
\text { OPR }\end{array}$ & $\begin{array}{l}\text { DAC, } \\
\text { Axial-stage }\end{array}$ & $\begin{array}{l}\text { CFM56, } \\
\text { GE90, } \\
\text { V2500-A5 }\end{array}$ \\
\hline $\begin{array}{l}\text { High Speed } \\
\text { Research (HSR) }\end{array}$ & $\begin{array}{l}1991- \\
1999\end{array}$ & SST & $\begin{array}{l}\text { LPP, } \\
\text { rich quick- } \\
\text { quench lean } \\
\text { (RQL) }\end{array}$ & DLE \\
\hline $\begin{array}{l}\text { Advanced } \\
\text { Subsonic } \\
\text { Transport (AST) }\end{array}$ & $\begin{array}{l}1994- \\
1999\end{array}$ & 60 OPR & TALON II & $\begin{array}{l}\text { PW4100, } \\
\text { PW6000, } \\
\text { GEnx }\end{array}$ \\
\hline $\begin{array}{l}\text { Ultra Efficient } \\
\text { Engine } \\
\text { Technology } \\
\text { (UEET) }\end{array}$ & $\begin{array}{l}2000- \\
2004\end{array}$ & 60 OPR & $\begin{array}{l}\text { Twin- } \\
\text { annular } \\
\text { premixing } \\
\text { swirler } \\
\text { (TAPS), } \\
\text { TALON X }\end{array}$ & $\begin{array}{l}\text { GEnx } \\
\text { GTF }\end{array}$ \\
\hline $\begin{array}{l}\text { Environmentally } \\
\text { Responsible } \\
\text { Aviation (ERA) }\end{array}$ & $\begin{array}{l}2010- \\
2015\end{array}$ & 55 OPR & $\begin{array}{l}\text { Partial- } \\
\text { premix, } \\
\text { LDI }\end{array}$ & \\
\hline
\end{tabular}

Table 1: NASA's Combustor-Technology-Focused Programs, Concepts, and Legacy

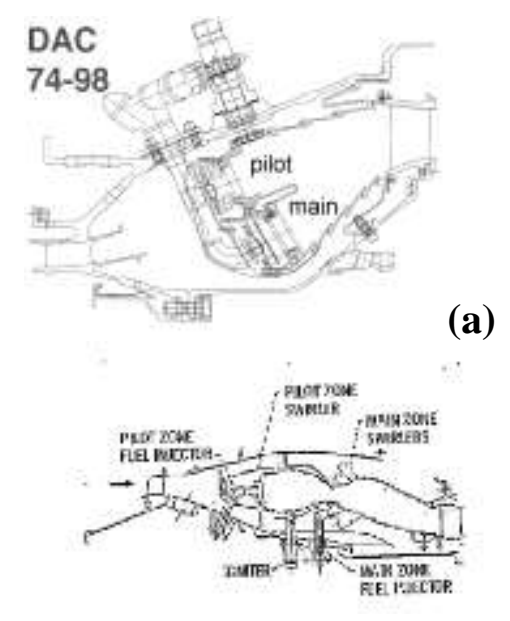

(b)
Fig. 9 - (a) Dual-Annular Combustor , (b) Vorbix Combustor (Jones et al., 1978) 
fuel lean, which produced lower NOx emissions at cruise and high power conditions. However, fuel-lean combustion is known to suffer from high CO and THC emissions at lowpower conditions. Therefore, fuel-lean concepts typically are staged in which combustion is separated into two or more zones. Both of these partially-lean-burn concepts employed a fuel-lean main zone that was fueled only at high and cruise power conditions and a fuel-rich pilot zone that was fueled at all conditions. This staged combustion allowed simultaneous lowering of NOx, CO, and THC emissions and smoke.

The radially-staged DAC concept was further refined under NASA's follow-on Energy Efficient Engine ( $E^{3}$ ) Program. The lowered emissions came because the DAC burned with more uniform temperature distribution. But along with better liner installation, the $\mathrm{E}^{3}$ combustor's required maintenance inspection time-span increased six-fold due to better air

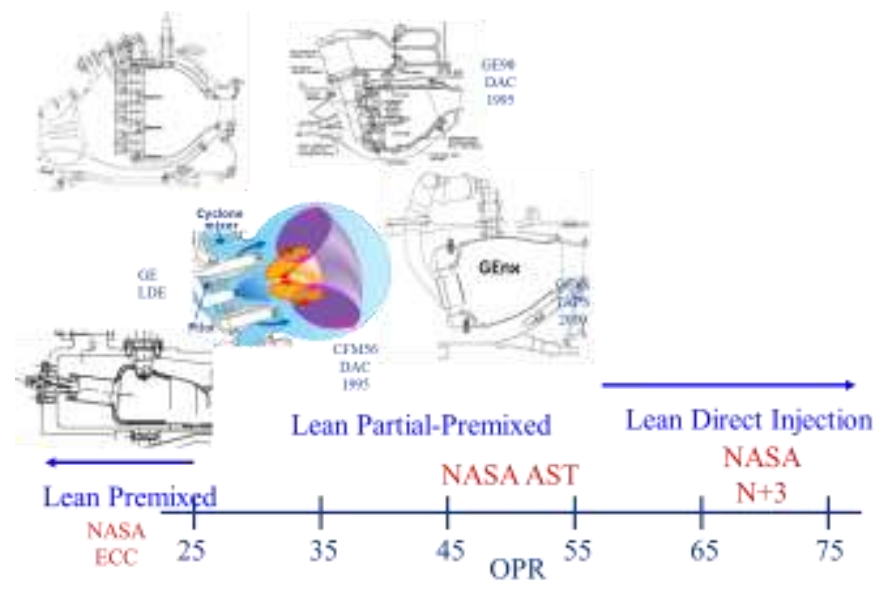

Fig. 10 Technology Advancement-NASA ECC and EEE Programs

distribution (Burris et al. 1984). The DAC concept was applied to the engines developed by GE during that time frame (Fig. 10). The ECC's Vorbix did not turn into a product directly. It had a fuel-rich pilot zone followed axially by a fuel-lean main stage downstream (Roberts et al. 1976). In NASA's following $\mathrm{E}^{3}$ Program, $\mathrm{P} \& \mathrm{~W}$ developed the technology further, and the concept of a lean-burning axiallystaged combustor showed its conceptual lineage in the engine jointly developed by P\&W and Rolls-Royce that had lower NOx levels. Several factors contributed to the low NOx levels. First the engine was more efficient then the engines of that timeframe. However, OPR and combustion temperatures were also higher, challenging the combustor technology. To address the higher temperatures, $\mathrm{P} \& \mathrm{~W}$ introduced their Floatwall $^{\mathrm{R}}$ double wall combustor design, which reduced required cooling air, making the cooling air available to reduce emissions. Further, $\mathrm{P} \& \mathrm{~W}$ was taking the initial steps to reduce residence time and improve mixing that eventually led to the current low-NOx TALON (Technology for Advanced Low NOx) designs. Also in that timeframe, $\mathrm{P} \& \mathrm{~W}$ developed a rich-quench-lean (RQL)staged combustor option that managed the residence times in the various combustion zones and delivered significantly lower NOx. However, despite satisfactory technical performance, this rich-staged combustor option was not developed further or commercialized because of the added marginal cost.

In 1994, NASA's Advanced Subsonic Technology (AST) Program engaged the industry to develop technologies to improve fuel efficiency by increasing the OPR from the previous engine generation's 25 to $60-75$. The higher OPR made it much more difficult to contain NOx level without changing the fuel injection concept. NASA Glenn has collaboratively worked with Pratt \& Whitney to carry out basic computational as well as experimental research to develop a fundamental understanding of a concept, RQL burning technology also aimed at reducing NOx. One advantage of the RQL scheme was that auto-ignition would not pose a problem at the higher OPR condition. Pratt \& Whitney developed the RQL concept further by adjusting the airflow and optimizing it into their TALON (Technology for Advanced Low NOx) II combustor for commercial service by the end of the decade.

By far the most notable outcome from AST was GE's (Twin Annular Premixing Swirler (TAPS) injector concept. Due to the radial staging, GE's lean-burn DAC had higher CO and THC and a skewed temperature profile. By nesting the pilot injector concentrically inside their fuel injector's main circuit with a partially premixed fuel-air stream, the TAPS had a more uniform temperature distribution. The mostly lean dome gained the high-power low emission as well as retaining the low-power stability. The much shorter premixing distance in the TAPS cyclone main injector alleviated the flashback issue with LPP. The TAPS lean operation during cruise-power lowers its NOx level to about half of a comparable RQL. Technology advancement of both LPP and RQL concepts starting from fundamental understanding through the various stages of the Technology Readiness Levels (TRLs) is shown in Figs. 11 and 12, respectively.

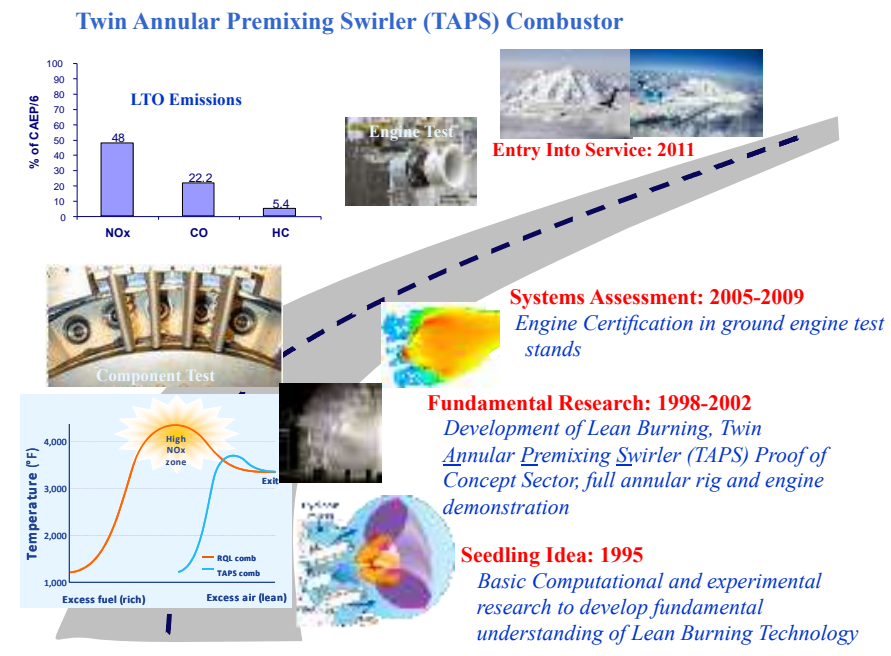

Fig. 11 Advancement of LPP Technology to Flight

The Ultra Efficient Engine Technology Program picked up AST's combustor work in 2000. P\&W continued their RQL contracted work by further improving the rich-zone fuel-air mixture uniformity and shortening the residence time 


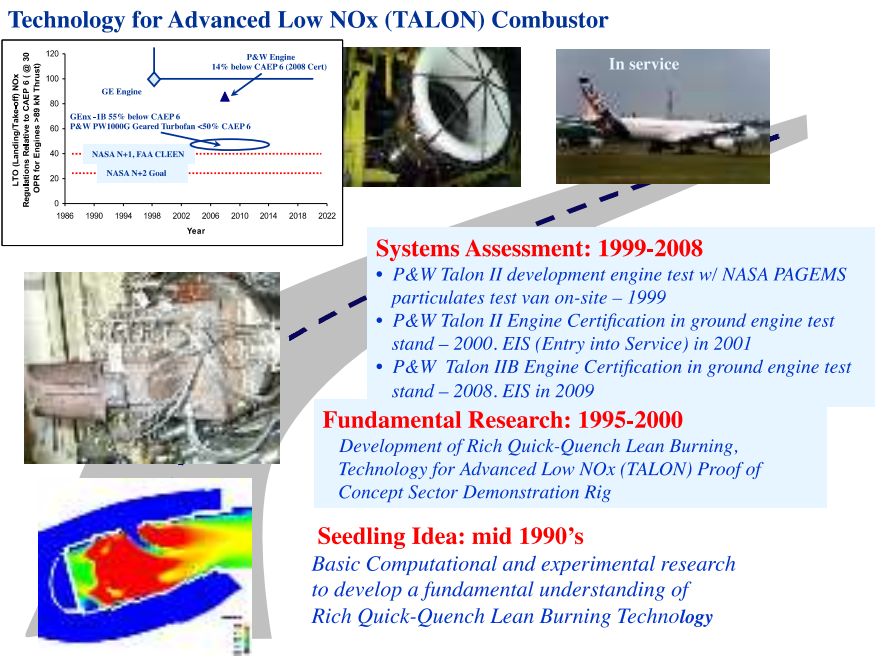

Fig. 12 Advancement of RQL Technology to Flight

in the lean-burn phase. Along with advanced wall cooling and optimized lean-zone mixing, their research contributed to the TALON X combustor (McKinney et al. 2007) to be used in P\&W's latest engines. For their part, GE improved their TAPS concept and continued to use in their engines (Dodds 2005; Foust et al. 2012).

\section{Current Research Efforts}

NASA's aeronautics research programs were restructured in 2005 by the Associate Administrator for the Aeronautics Research Mission Directorate (ARMD). Aeronautics research was reorganized into four programs: the Fundamental Aeronautics Program (FAP) to conduct long-term, cuttingedge research in the core competencies of aeronautics in all flight regimes, the Aviation Safety Program (AvSP) to develop unique safety-related research capabilities to improve the safety of new and legacy vehicles as well as to overcome safety technology barriers, the Airspace Systems Program to address air traffic management $R \& D$ needs, and the Aeronautics Test Program (ATP) to protect and maintain key research and test facilities. The FAP produced knowledge, data, capabilities, and design tools in the old NACA style. Industry partnerships were to be transformed from near-term, evolutionary procurements to long-term, intellectual partnerships to provide long-term, stable investment in capabilities that would benefit all of the industry. In 2010, a fifth program, the Integrated Systems Research Program (ISRP) was added to mature technologies that had already proven their merit at the fundamental research level and to transition them more quickly to the aviation community. The emphasis is on integrated system-level research of interest and importance to the aviation stakeholder community. The first project initiated under this program was the Environmentally Responsible Aviation (ERA) project to mature the technologies that were developed under the FAP to a systemlevel aimed at meeting the mid-term $(\mathrm{N}+2)$ goals of fuel burn, noise, and emission reductions (Alonso, 2008).

Under the ERA project, NASA initiated a third (latest) round of emissions reduction technology development in 2010 to reduce the emissions from 50\% LTO-NOx level of the current generation to $75 \%$ below CAEP/6. This continuing NOxreduction effort is even harder under ERA than it was under previous programs. After 3 decades, the existing NOx level was already pretty low, and it was becoming increasingly difficult to obtain further reduction. At the same time, ERA's system-level goal also includes a $40 \%$ reduction in fuel consumption for the vehicle. Although much of these savings may be taken up by airframe drag reduction, the contribution required from engine efficiency improvement means increasing the engine OPR to about 55 from the current stateof-the-art (SOA) value of around 45 . This increased combustor pressure and temperature also increases the NOx formation rate. In addition, these concepts also are required to operate on a 50/50 blend of native hydrocarbon fuels. An additional goal of halving the cruise-level NOx from the existing state of the art was added to the LTO NOx.

The ERA effort is aimed at low-NOx fuel-flexible combustor technologies for the next-generation commercial aircraft engines in the 2020 timeframe. This effort has engaged industry partners GE and P\&W to develop combustor concepts that can achieve the ERA emission goals mentioned above (75\% LTO NOx reduction below CAEP/6 standard). These two contracts are cost-shared and leveraged concepts from past NASA-sponsored research and industry partners' internally-developed technology. The scope covers the full set of combustor challenges with full-sized injectors, liners, as well as the challenge to manage combustor system-level dynamics. Phase I of this effort (concluded in 2012) has resulted in GE and $\mathrm{P} \& \mathrm{~W}$ demonstrating multi-cup sector combustor configurations (TRL 4) both based on partially premixed lean-burn design concepts that met the emission goal (Lee et al. 2013). Phase II, just concluded in 2015, has resulted in a successful demonstration of this technology by $\mathrm{P} \& \mathrm{~W}$ in a full-annular combustor configuration (TRL 5) and could lead to potentially an engine core demonstration (TRL 6 ) and engine product developments in the future (see Fig. 13).

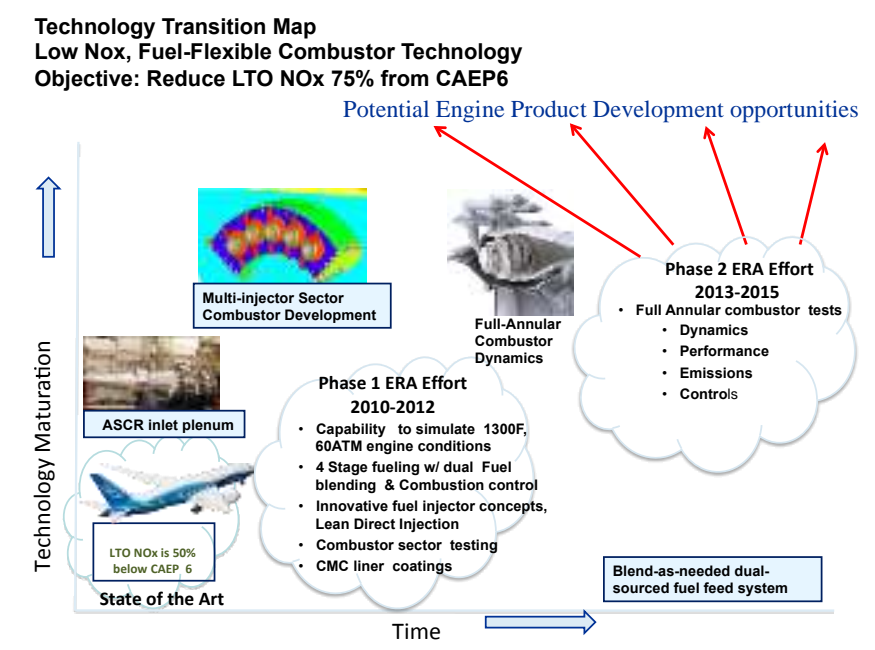

Fig. 13 NASA ERA Project Combustor Technology Roadmap 
GE's concept development started with the legacy TAPS design that was developed via multiple technology and commercial programs, and the capabilities of this technology were advanced to meet the aggressive ERA $(\mathrm{N}+2) \mathrm{NOx}$ and performance goals. The basic concept behind GE's combustor design is to increase the fraction of air used for premixing in the front end of the combustor beyond that of previous TAPS designs (70\%), while simultaneously adding features that further enhance the fuel-air mixing. Increased premixing air can present a significant challenge to both operability (efficiency and combustion dynamics) as well as durability (less cooling air for the combustor dome and liner). To meet durability challenges, high-temperature ceramic matrix composite $(\mathrm{CMC})$ materials with advanced cooling are utilized for the combustion liners. The new combustor design concepts were benchmarked against data from previous successful development programs. A series of combustion tests

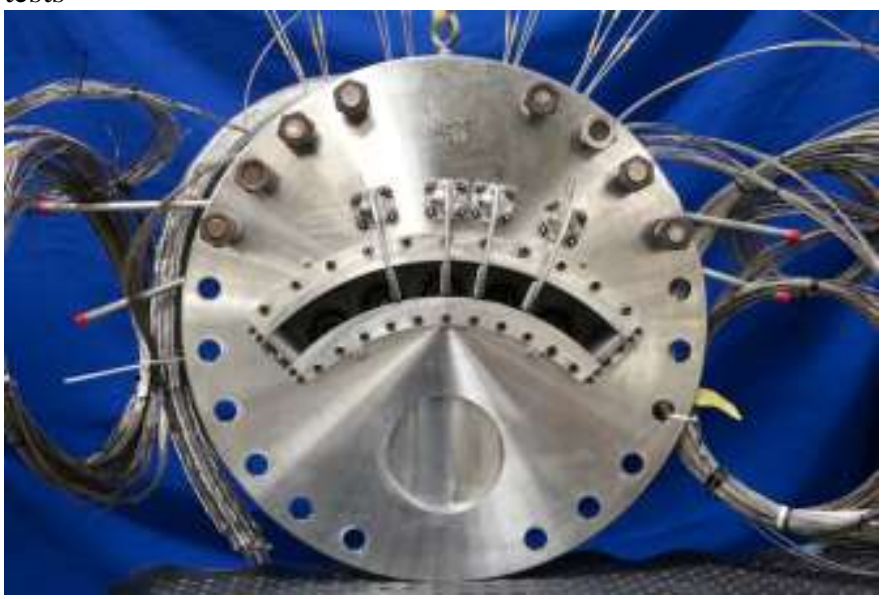

Fig. 14 GE 5-cup Combustor Sector

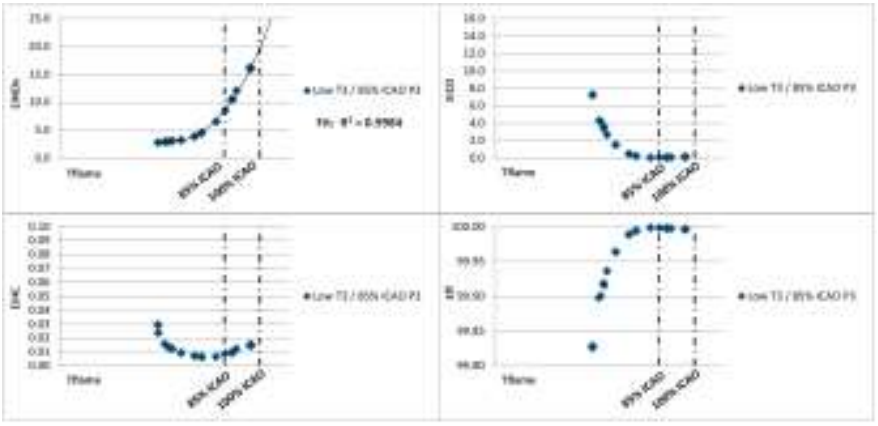

\section{Fig. 15 Emission Data for $85 \%$ and $100 \%$ ICAO Points}

ultimately provided the opportunity to down select and further optimize the designs, leading up to the testing of one final configuration in a new 5-cup sector configuration (Fig. 14) in the NASA ASCR (Lee et al. 2013). The combustor emission data were obtained at four different operating conditions: 7\% (idle), 30\% (approach), 85\% (climb up), and 100\% (take off) ICAO points. Fig. 15 shows the emission data for $85 \%$ and $100 \%$ condition, and Table 2 summarizes the LTO NOx emission

\begin{tabular}{|c|c|c|c|c|}
\hline $\begin{array}{c}\% \\
\mathrm{ICAO}\end{array}$ & $\begin{array}{l}\text { Time } \\
\text { [min] }\end{array}$ & $\begin{array}{c}\text { EIN } \\
\text { Ox } \\
\end{array}$ & $\begin{array}{l}\text { dp/F00 (NOx } \\
\text { in grams / } \\
\text { Engine Thrust } \\
\text { in KN) }\end{array}$ & $\begin{array}{c}\% \\
\text { CAEP/ } \\
6 \\
\end{array}$ \\
\hline 100 & 0.7 & 17.6 & \multirow[b]{4}{*}{20.6} & \multirow[b]{4}{*}{18.9} \\
\hline 85 & 2.2 & 7.9 & & \\
\hline 30 & 4 & 13.2 & & \\
\hline 7 & 26 & 5.8 & & \\
\hline
\end{tabular}

Table 2: Summary of LTO NOx Results for the GE N+2 5-Cup Sector

indices. From the summarized values, it can be seen that the GE combustor delivered 19\% CAEP/6 NOx, surpassing the $\mathrm{N}+2$ goal of 25\% CAEP/6, with good combustion efficiencies and acceptable dynamic pressures for this stage of development.

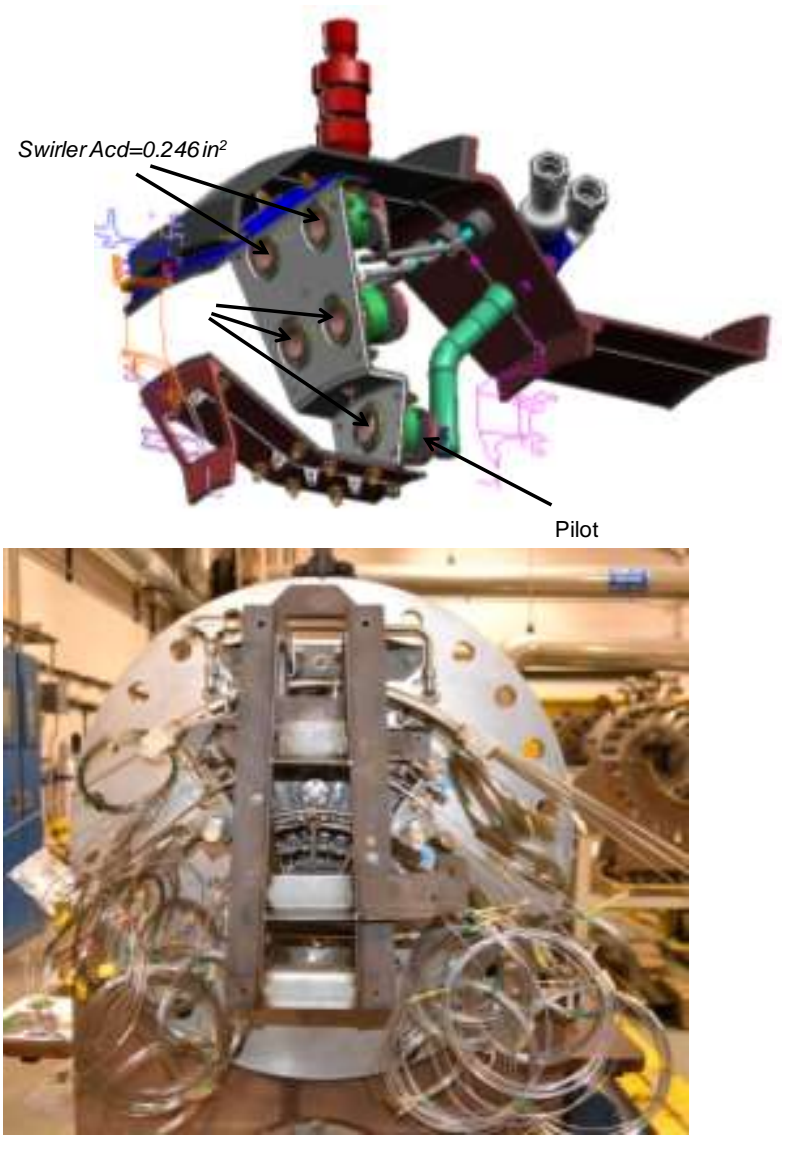

Fig. 16 Pratt \& Whitney 3-Cup Low NOx Combustor Sector in NASA ASCR

Pratt \& Whitney chose the axially staged combustor and decided to implement it in a simpler fashion than the version developed earlier in their joint engine development with RollsRoyce. Various fuel-air mixer designs were then created that 
achieved the desired level of mixing. The resulting mixers were then evaluated at the United Technology Research Center (UTRC) to determine if they achieved the desired level of emissions. Axially Controlled Stoichiometry (ACS) concept was chosen for testing at NASA (Lee et al. 2013). The arrangement of the separation of the pilot and the main provides for efficiency and stability at low power, and stability at all operating conditions. Mixing of the pilot and main is controllable according to PW experience in the design and manufacture of axially staged combustion systems. The ACS concept was then implemented in a 3-sector arc rig that was tested first at UTRC, then at NASA in the ASCR facility (Fig. 16).

\% CAEP6 LTO Emissions in a N+2 Cycle

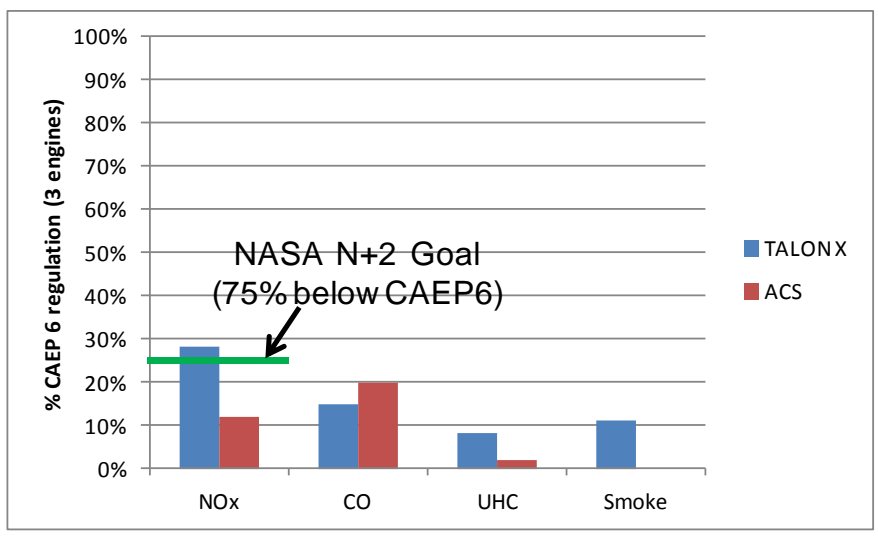

Cruise NOx in a $\mathrm{N}+2$ Cycle

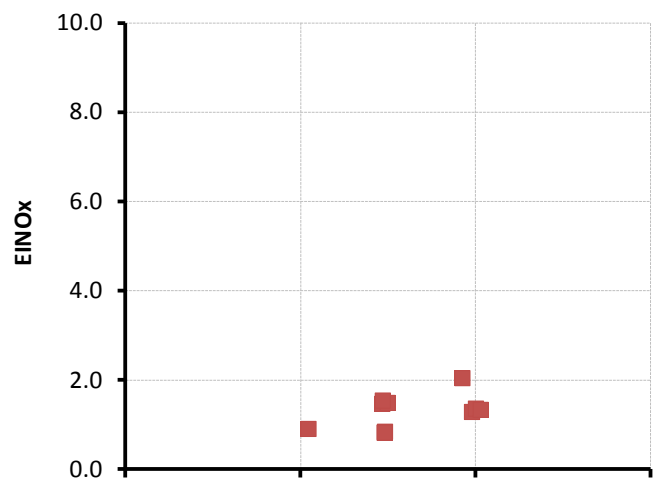

Fig. 17 The P\&W ACS 3-Cup Combustor Sector NOx Emissions

Emissions were measured at real engine operating conditions for idle, take-off, climb, and approach, and a NOx value of $88 \%$ below CAEP/6 limit was calculated using an N+2 cycles based on an advanced Geared Turbo Fan. Performance with respect to all CAEP regulated emissions are shown in Fig. 17. The results show that the $\mathrm{P} \& \mathrm{~W}$ combustor sector test demonstrated $12 \%$ CAEP/6 NOx, surpassing the ERA $(\mathrm{N}+2)$ goal of $25 \%$ with good combustion efficiencies and acceptable dynamic pressures as well. More details can be obtained from the contractor reports that could be publicly accessible to be published by GE and P\&W in the next few years.

\section{Future Research Plans}

Based on the global energy demand forecast, there will be extraordinary pressure on the transportation industry in general, and aviation in particular, to advance technologies to improve fuel efficiency. Aircraft engine technologies that will increase overall efficiency of the engines will be the focus of the aviation propulsion research community for the foreseeable future. Although alternative power sources such as fuel cells will be developed over the long-term, in the nearterm the gas turbine engine will be the choice of propulsion for aviation, and the research will be focused on improving the fuel efficiency (overall efficiency). Material and design improvements are expected to allow higher pressure and higher temperature core engines to improve thermal efficiency. Higher OPRs needed for higher efficiency will lead to a serious challenge in meeting the emission reduction goals because of the high combustor temperatures resulting from the high OPR. In addition, future environmental regulations are expected to be increasingly stringent and include particulate and contrail as well as oxides of sulphur. Future combustor designs need to address these challenges and require the tools and technologies to meet these stringent emission limits. NASA is expected to lead the development of the necessary tools and technologies and advance the TRL of advanced combustor concepts to enable smooth transfer of technology to the propulsion industry. NASA Glenn has already initiated the development of experimental and computational tools to understand the key phenomena influencing particulate and contrail emissions in a controlled low-TRL environment. Low-carbon propulsion continues to be one of the key research themes of the NASA ARMD, and the Glenn Research Center will continue research and technology development in the areas of drop-in alternative fuels as well as other low-carbon alternative fuels by characterizing these alternative fuels and investigating their application for future combustor designs experimentally as well as computationally.

\section{Summary}

A brief outline of low-emission combustor research and technology development efforts at NASA Glenn Research Center to meet the high-level emission reduction goals of the NASA Aeronautics Research Mission Directorate for aviation propulsion has been presented. NASA Glenn's combustion research and technology advancement efforts over the past 5 decades as well as current and future plane to reduce the impact of aviation emissions on the environment have been highlighted. Advancements in technology and the dramatic reduction of emissions have been achieved through successful partnership with the industry, which is expected to continue in the future. Participation of industry at the appropriate phase of technology progression of starting from fundamental understanding through the various stages of the Technology Readiness Levels (TRL) has been a key factor in NASA Glenn' success in effectively transferring the technology to industry. Its unique core competencies have positioned NASA Glenn to strategically encourage and accommodate partnerships with industry, academia, and other government agencies. NASA Glenn continues, as the world leader, to play 
a key role in advancing the technology to meet the performance and increasingly stringent environmental compatibility requirements of the future aviation propulsion systems.

\section{References}

Alonso, J. (2008). "Program Highlights Fundamental Aeronautics Program.” NASA Fundamental Aeronautics Program Annual Meeting, Atlanta, GA, October 7-9, 2008.

Bianco, J. (1995). "NASA Lewis Research Center's Combustor Test Facilities and Capabilities." NASA TM106903.

Burris, D. L., Chahrour, C. A., Foltz, H. L., Sabla, P. E., Seto, S. P., and Taylor, J. R. (1984). "Energy Efficient Engine combustor test hardware detailed design report." NASACR-168301, March 01, 1984.

Cai, J., Jeng, S.-M., and Tacina, R., "The Structure of a SwirlStabilized Reacting Spray Issued from an Axial Swirler," AIAA-2005-1424, 43rd AIAA Aerospace Science Meeting and Exhibit, 10-13 January 2005, Reno, NV.

Dodds, W.J., Ekstedt, E.E., Bahr, D.W., and Fear, J.S. (1982). "NASA /General Electric Broad-Specification Fuels Combustion Technology Program-Phase I Results and Status." AIAA-82-1089, 1982.

Dodds, W. (2005). "Twin Annular Premixing Swirler (TAPS) Combustor." The Roaring 20th Aviation Noise \& Air Quality Symposium.

Foust, M.J., Thomsen, D., Stickles, R., Cooper, C., Dodds, W. (2012). "Development of the GE Aviation Low Emissions TAPS Combustor for Next Generation Aircraft Engines." Paper AIAA-2012-0936, Nashville, TN, January 9-12.

Jones, R.E., and Grobman, J. (1973). "Design and evaluation of combustors for reducing aircraft engine pollution." NASA TM-X-68192.

Jones, R.E., Diehl, L.A., Petrash, D.A., and Grobman, J. (1978). "Results and Status of the NASA Aircraft Engine Emission Reduction Technology Programs.” NASA TM 79009.

Lee, C-M., Chang, C., Kramer, S., and Herbon, J. (2013), "NASA project develops next generation low-emissions combustor technologies," Paper AIAA 2013-0540, Jan. 2013.

Liu, N.-S., Shih, T.-H., and Wey, T. (2007). "Comprehensive Combustion Modeling and Simulation: Recent Progress at NASA Glenn Research Center." ISABE-2007-1268, 18th International Symposium on Air Breathing Engines, September 2-7, Beijing, China.

Liu, N.-S. (2011). "Assessment and Improvement of Engineering Simulation for Multiphase Turbulent Combustion in a Lean Direct Injection Combustor." ISABE-2011-1108, 20th International Symposium on Air Breathing Engines, September 12-16, Gothenburg, Sweden.

McKinney, R.G., Sepulveda, D., Sowa, W. and Cheung, A.K. (2007). "The Pratt \& Whitney TALON X low emissions combustor: revolutionary results with evolutionary technology." Paper AIAA-2007-386, The 45th AIAA Aerospace Sciences Meeting, January, 2007.

Mularz, E. J., Gleason, C. C., and Dodds, W. J., (1978). "Combustor Concepts for Aircraft Gas Turbine LowPower Emissions Reduction.” NASA TM 78875.

NASA's New Aeronautics Research Program Overview, presented at the AIAA Aerospace Sciences Meeting, Reno, NV, Jan. 2007, http://www.aeronautics.nasa.gov/pdf/armd_overview_reno_4.pdf

Niedzwiecki, R.W., and Jones, R. (1974). "The Experimental Clean Combustor Program - Description and Status." NASA TM X-71547.

Papathakos, L. C., and Jones R. (1973). "Use of An AirAssisted Fuel Nozzle to Reduce Idle Emissions of A JT8D Engine Combustor." NASA TM X-2946.

Parker, R. J. (2015), "Vision 20 and Beyond," Plenary presentation, $22^{\text {nd }}$ International Society of Air Breathing Engines (ISABE) Conference, Oct. 25 - 30, 2015, http://isabe2015.org/InvitedLectures.aspx

Raju, M.S., and Bulzan, D. (2011). "Assessment of Some Atomization Models used in Spray Calculations." NASA/TM-2011-217029.

Remy, S. (2015), "Unlocking the Dilemma of Ecoefficiency," Plenary presentation, $22^{\text {nd }}$ International Society of Air Breathing Engines (ISABE) Conference, Oct. $25-30,2015$, http://isabe2015.org/InvitedLectures.aspx

Roberts, R., Peduzzi, A., and Vitti, G.E. (1976). "Experimental Clean Combustor Program - Phase II Final Report.” NASA CR-134969.

Rudey, R.A. and Kempke, E.E., Jr (1975) “Technology for reducing aircraft engine pollution.” NASA TM-X-71670.

Rudey, R.A. (1976). "Status review of NASA programs for reducing aircraft gas turbine engine emissions." NASA TM-X-71861.

Runnemalm, H. (2015), “Technology Provider for Affordable and Environmental Compatible Propulsion Solutions from a GKN Aerospace Perspective," Plenary presentation, $22^{\text {nd }}$ International Society of Air Breathing Engines (ISABE) Conference, Oct. 25 - 30, 2015, http://isabe2015.org/InvitedLectures.aspx

Shih, T.-H., and Liu, N.-S. (2009). "A Nonlinear Dynamic Subscale Model for PRNS/VLES of Internal Combustor Flows." AIAA-2009-0467, 47 ${ }^{\text {th }}$ AIAA Aerospace Sciences Meeting, 4-8 January, Orlando, FL.

Singh, R (2015), "The Future Journey of Civil Aerospace Weather, Environment and Climate," Plenary presentation, $22^{\text {nd }}$ International Society of Air Breathing Engines (ISABE) Conference, Oct. 25 - 30, 2015, http://isabe2015.org/InvitedLectures.aspx

Szaniszlo, A.J. (1979). "The Advanced Low-Emissions Catalytic-Combustor Program Phase I - Description and Status." NASA TM-79049.

"Supersonic Cruise Research '79 Part 1" (1979), NASA CP2108 .

Wey, T., and Liu, N.-S. (2011). "Simulation of an Integrated Lean-Direct Injection Combustor and a Stage of StatorRotor Turbine." AIAA-2011-705, 49 ${ }^{\text {th }}$ AIAA Aerospace Sciences Meeting, 4-7 January, Orlando, FL. 